\title{
Preventive care for physical activity and fruit and vegetable consumption: a survey of family carer expectations of health service delivery for people with a mental health condition
}

Jacqueline M. Bailey ${ }^{1,2^{*}}$ (D) Tara L. Clinton-McHarg ${ }^{1,2}$, Paula M. Wye $e^{1,2}$, John H. Wiggers ${ }^{2,3,4}$, Kate M. Bartlem ${ }^{1,2}$ and Jennifer A. Bowman ${ }^{1,2}$

\begin{abstract}
Background: Chronic disease is a leading cause of death globally, where inadequate fruit and vegetable consumption and inadequate physical activity are consistently implicated as key contributing risk factors for such diseases. People with a mental health condition are reported to experience a higher prevalence of such risks and experience an increased morbidity and mortality from resultant chronic disease. Despite guidelines identifying a need for services accessed by people with a mental health condition to provide care to address such health risk behaviours, sub-optimal care is frequently reported suggesting a need for innovative strategies to increase the provision of physical health care. An exploratory study was conducted to examine: 1) family carers' expectations of care provision regarding fruit and vegetable consumption and physical activity by health and community services for people with a mental health condition; 2) carer's own health risk behaviour status and perceptions of the influence of the health risk behaviours on mental health; and 3) possible associations of socio-demographic, clinical and attitudinal factors with carer expectations of care provision for fruit and vegetable consumption and physical activity.
\end{abstract}

Methods: Family carers $(n=144)$ of a person with a mental health condition completed a cross-sectional survey. Participants were members of a mental health carer support organisation operating in New South Wales, Australia.

\footnotetext{
* Correspondence: jacqueline.m.bailey@uon.edu.au

'School of Psychology, Faculty of Science and Information Technology, The University of Newcastle, University Drive, Callaghan, NSW 2308, Australia

${ }^{2}$ Hunter Medical Research Institute, Clinical Research Centre, Lot 1 Kookaburra Circuit, New Lambton Heights, NSW 2305, Australia

Full list of author information is available at the end of the article
}

(c) The Author(s). 2020 Open Access This article is licensed under a Creative Commons Attribution 4.0 International License, which permits use, sharing, adaptation, distribution and reproduction in any medium or format, as long as you give appropriate credit to the original author(s) and the source, provide a link to the Creative Commons licence, and indicate if changes were made. The images or other third party material in this article are included in the article's Creative Commons licence, unless indicated otherwise in a credit line to the material. If material is not included in the article's Creative Commons licence and your intended use is not permitted by statutory regulation or exceeds the permitted use, you will need to obtain permission directly from the copyright holder. To view a copy of this licence, visit http://creativecommons.org/licenses/by/4.0/. The Creative Commons Public Domain Dedication waiver (http://creativecommons.org/publicdomain/zero/1.0/) applies to the data made available in this article, unless otherwise stated in a credit line to the data. 
(Continued from previous page)

Results: A high proportion of participants considered care for fruit and vegetable consumption and physical activity respectively should be provided by: mental health hospitals (78.5, 82.7\%); community mental health services (76.7, 85.9\%); general practice (81.1, 79.2\%); and non-government organisations (56.2, 65.4\%). Most participants perceived adequate fruit and vegetable consumption (55.9\%), and physical activity (71.3\%) would have a very positive impact on mental health. Carers who perceived adequate fruit and vegetable consumption and physical activity would have a positive impact on mental health were more likely to expect care for such behaviours from some services.

Conclusions: The majority of participants expected care for fruit and vegetable consumption and physical activity be provided by all services catering for people with a mental health condition, reinforcing the appropriateness for such services to provide physical health care for clients in a systematic manner.

Keywords: Chronic disease risk behaviours, Caregiver, Mental illness, Health services, Fruit and vegetable consumption, Physical activity

\section{Background}

Physical chronic diseases, such as cardiovascular diseases, cancer, and diabetes, are a leading cause of death globally and contributed to $71 \%$ of deaths in 2017 [1, 2]. Chronic conditions such as overweight and obesity (conservatively measured by Body Mass Index [BMI]) were also estimated to account for 4.7 million deaths globally in 2017 and 148 million Disability Adjusted Life Years (DALYs, sum of years lived with a disability and years of life lost) [3]. In 2014, 38 to $40 \%$ of adults were overweight and 11 to $15 \%$ obese; with the worldwide prevalence of obesity nearly doubling between 1980 and 2014, [1] and continuing to increase [4]. Such prevalence estimates continue to increase, with 2016 prevalence estimates of obesity ranging from 20 to $36 \%$ among adults in Australia, United Kingdom, United States, Canada, and many European nations [4].

Compared to these global figures, the reported figures in Australia are somewhat higher, with physical chronic diseases contributing to $87 \%$ of deaths in 2015 [5]. The prevalence of diabetes in Australia has tripled over the last 25 years with $6.1 \%$ (1.2 million people) of the adult population reported to have the condition in 2015 [5]. A recent study of more than 10 million adults from 239 prospective studies found that Australian and New Zealand adults with a BMI above the 'normal weight' range (BMI $>25 \mathrm{~kg} /$ $\mathrm{m} 2$ ) had an increased risk of death from all causes of $31 \%$, for each $5 \mathrm{~kg} / \mathrm{m} 2$ increase in BMI [6]. Further, compared to people with a 'normal weight' BMI, life expectancy was reduced by 2-4years for people with class I obesity $(\mathrm{BMI}=30-34.99)$, and by $8-10$ years for people with class III obesity (BMI = > 39.99) [7].

Inadequate physical activity and inadequate fruit and vegetable consumption are two modifiable health risk behaviours that are consistently implicated as contributing to the incidence of physical chronic disease and overweight and obesity $[3,8,9]$. Inadequate physical activity is a risk factor for the development of chronic diseases such as ischemic heart disease, stroke, diabetes mellitus, and cancer, as well as the development of conditions that contribute to these chronic diseases such as overweight, obesity and hypertension $[3,10]$. Similarly, inadequate fruit and/or vegetable consumption are risk factors for the development of obesity, and chronic diseases such as: ischemic heart disease; stroke; diabetes mellitus; stomach, oesophageal, colorectal, and lung cancer [3, 8, 9, 11-13]. Additionally, the combination of multiple health risk behaviours increases the risk of developing chronic disease and resultant mortality $[14,15]$. National guidelines vary slightly between countries regarding what is considered to be an inadequate level of physical activity or inadequate fruit and vegetable consumption [16-22]. In Australia, current national guidelines state that the following behaviours may place an individual at risk of developing a chronic disease: 1 ) consuming less than five vegetable or two fruit servings per day [23]; 2) engaging in less than 150 to $300 \mathrm{~min}$ of moderate intensity physical activity (e.g. brisk walking, golf) or 75 to $150 \mathrm{~min}$ of vigorous intensity physical activity (e.g. jogging, aerobics, digging), or an equivalent combination each week; and participating in muscle strengthening activities on less than 2 days each week [24].

The prevalence of overweight and obesity, [25-27] inadequate physical activity $[28,29]$ and inadequate fruit and vegetable consumption $[28,29]$ is higher among people with a mental health condition than those without. Internationally and in Australia, people with a mental health condition experience increased rates of physical chronic disease, and resultant morbidity, mortality and reduced life expectancy compared to people without a mental health condition [30-32]. Research among this population group utilises various terminology such as 'mental illness' or 'mental disorder', the term 'mental health condition' will be used throughout this study to define mental health conditions commonly experienced by individuals accessing adult mental health services; that is, categories of mental illness outlined in the Diagnostic and Statistical Manual of Mental Disorders-5 [33] not including neurodevelopmental or 
degenerative disorders (for example, not including autism and dementia, but including but not limited to: schizophrenia, depression, anxiety, and personality disorders). A systematic review that included four studies of national survey data found that people with severe mental health conditions such as schizophrenia are significantly more likely to be overweight or obese than other members of the population [32]. One of the studies included in the review found that Australian's who completed the national survey of psychosis in 2010 were two times more likely to be obese (BMI > 30) compared to the general population in the same time period [34, 35]. Additionally, having a chronic mental health condition, has been independently linked to the development of physical chronic diseases such as cardiovascular disease, [30-32, 36] demonstrating the complexities in addressing the development of chronic disease among this group.

Furthermore, the research literature has also explored the bi-directional impact of physical and mental health. For example, a systematic review and meta-analysis of 26 longitudinal studies among various populations, reported consistent evidence across all populations that smoking cessation was associated with significant reductions in depression, anxiety, stress; and increased psychological wellbeing and positive affect compared to continued smoking [37]. Systematic review evidence similarly suggests that physical activity reduces anxiety symptoms in both people without a mental health condition, [38] and those with anxiety disorders, $[39,40]$ depression, $[38,40]$ schizophrenia, $[38,40]$ post-traumatic stress disorder, $[40]$ and substance dependence [40]. Further, a meta-analysis of 49 prospective studies found physical activity had a protective effect against the emergence of depression in youths, adults, and elderly persons [41]. Such research highlights the benefits for physical and mental health that can be achieved through addressing health risk behaviours.

In the research literature, the prevalence of inadequate physical activity $[28,29,42-47]$ and inadequate fruit and vegetable consumption $[28,29,45,46]$ among people with a mental health condition is consistently reported to be higher than people without a mental health condition, and may be highest for people with mental health conditions requiring inpatient care. This higher prevalence of risk behaviour is demonstrated by comparing the results of three studies conducted in the same geographic region of Australia, utilising comparable methodologies, and consistent definitions of risk behaviours as per national guidelines. Cross-sectional surveys conducted amongst general community health clients $(n=1284)$, community mental health clients $(n=558)$, and psychiatric inpatients $(n=$ 2075) revealed a higher prevalence of risk behaviours among community mental health clients compared to general health clients, and further increased risk for psychiatric inpatients for: inadequate fruit and/or vegetable consumption ( $81 \%$ vs $88 \%$ vs $95 \%$ ), and inadequate physical activity ( $28 \%$ vs $47 \%$ vs $50 \%$ ) [48-50].

Internationally and in Australia, guidelines and policies acknowledge the need to provide care to all health service clients who may be at risk for inadequate physical activity and/or fruit and vegetable consumption, [51-53] with additional guidelines and policies existing specifically for clients with a mental health condition [54, 55]. Despite the existence of these guidelines and policies, the reported effectiveness of the provision of preventive care and lifestyle interventions in mental health services to improve such health risk behaviours, [56-60] and the reported interest of mental health service clients in receiving support to improve these behaviours, $[49,61]$ sub-optimal care for health risk behaviours from general practitioners [62] and community and inpatient mental health services is consistently reported [63]. For instance, a recent a meta-analysis of 26 studies found sub-optimal provision of care (less than $80 \%$ of clients in receipt of care) to address inadequate nutrition generally and physical activity across all elements of care (e.g. asking/assessing, advising, assisting, and arranging referral) in community, inpatient, and other mental health services [63]. A number of factors have been implicated as barriers to the provision of preventive care in mental health settings including: clinician attitudes and beliefs about their client's capability or interest in changing [64, 65]; as well as the risk behaviours of the clinician, where clinicians who are at risk for a particular behaviour themselves may be less likely to provide care to their client for that behaviour [66].

In addition to the existence of policies and guidelines surrounding the type of preventive care to be delivered to people with a mental health condition, guidelines also state the need to include a variety of stakeholders, including clients and their informal family carers, in the planning, development and implementation of mental health policy and practice [67-70]. A family or informal carer is an individual who provides support and assistance without payment to an individual with any physical or mental health condition or disability [71]. Inclusion of multiple stakeholders is recommended in order to deliver a holistic approach to mental health care and increase the effectiveness of health care service treatments and interventions [72-74]. For instance, the New South Wales (NSW) Carer Recognition Act states that carers should be engaged as important stakeholders in the provision of care, including the assessment, planning, delivery, and review of services provided to the person they care for, and should be included in care decision making [75].

The acknowledged role that family carers play in the provision of support to people with a mental health condition, suggests that an alignment between carer expectations 
regarding what type of care should be provided and the type of care that is actually delivered by services may contribute to service design which may lead to more positive outcomes for people with a mental health condition [76]. The importance of the carer viewpoint is evidenced by the National Mental Health Commission's 2017 establishment of the Equally Well Implementation Committee, which includes carer members, with the aim of bridging the physical and mental health sectors to ensure holistic care for people with a mental health condition [77].

To date however, there has been limited research undertaken with family carers to understand their expectations regarding what type of care to address the chronic disease risk behaviours should be provided to people with a mental health condition by health and community services. Only two previous studies have focused on this issue relevant to inadequate physical activity and nutrition generally [78-80]. One qualitative study from the US of 13 carers of older adults with serious mental illness found that carers reported a need for guidance from health care professionals regarding strategies to promote weight loss by their family member [78].

The second study, an Australian qualitative study of 31 family carers, reported a desire by carers to be informed about any health service interventions which aimed to address the physical health of the person they cared for so that carers could support such interventions [79]. Additionally, carers reported a desire for services accessed by their family member to provide holistic care, due to their awareness of the bidirectional relationship between physical and mental health. It has been found previously that carers are aware of the bidirectional relationship between physical and mental health, and this has been associated with carer expectations of smoking cessation care provision by services accessed by people with a mental health condition [80]. Further, carers have also reported that their capacity to support their family member in making health behaviour change is impacted by the need to maintain their own physical health and well-being [79]. These two previous studies were limited by small sample sizes, and their lack of focus on physical activity and fruit and vegetable consumption specifically. The absence of any quantitative studies limits understanding of the prevalence of the reported expectations among carers generally.

\section{Methods}

\section{Aims}

Given the limited research concerning carer expectations regarding health service delivery of care addressing client physical activity and nutrition risk behaviours (despite the existence of guidelines and policies championing for the inclusion of the carer perspective) for people with a mental health condition, a study was undertaken to examine: 1) family carers' expectations of care provision regarding fruit and vegetable consumption and physical activity by health and community services (mental health hospitals, community mental health services, general practice [GP], and non-government organisations [NGOs]) for people with a mental health condition; 2) carers' own health risk behaviour status and perceptions of the influence of fruit and vegetable consumption and physical activity on mental health; and 3) possible associations of socio-demographic, clinical and attitudinal factors with carer expectations of care provision for fruit and vegetable consumption and physical activity.

\section{Design and setting}

One hundred forty four family carers of adults with a mental illness in one non-metropolitan region in NSW, Australia completed a cross sectional survey from July to November 2013. The study was approved by the Hunter New England Human Research Ethics Committee (No. 13/06/19/5.11) and the University of Newcastle's Human Research Ethics Committee (No. H-2019-0141; refer to Additional file 1).

\section{Participants and recruitment}

Potential participants were identified through their membership of a non-government carer support organisation that provided free support services, advocacy, training and education to carers of people with a mental health condition [81]. The organisation had operated across the study region for approximately 10 years, in partnership with local mental health services, providing individual and group support. Any member of the public who was a carer of a person with any mental health condition was able to join the organisation without cost as a source of support for their role as a carer. Participants were eligible for the study if they were: 18 years or older and identified themselves as a family carer for someone with any mental health condition who was also over 18 years.

The carer organisation identified potential participants throughout the Hunter New England Local Health District based on members' previously recorded interest in research participation. The organisation mailed an invitation to participate in the study (Additional file 1), information statement (Additional file 1), survey instrument (Additional file 1) and reply-paid envelope to all such listed members. The invitation letter also included a web link for optional online survey completion. Potential participants who had not responded to the letter after one month were mailed a reminder letter. Most surveys were returned within one month; the remainder were received over a four month period. Additional participants were approached by research team members at carer support group meetings organised by or affiliated with the carer 
support organisation. Survey completion took approximately $28 \mathrm{~min}$.

\section{Measures}

Carers completed items assessing socio-demographic, clinical and health risk behaviours; which were modified from previous research [82]. Items examining the carer and family member relationship, perceptions regarding the impact of health risk behaviours on mental health, and carer expectations of care provision for health risk behaviours by services were developed with input from mental health staff and carers. Refer to supplementary material for the survey instrument.

\section{Socio-demographic and clinical characteristics}

Six items addressed the age, gender, employment, marital status, highest level of education achieved, and Aboriginal and/or Torres Strait Islander status of both the family carer and person with a mental health condition. Participants were also asked their postcode of residence to determine geographic remoteness and socio-economic index of disadvantage [83, 84].

Participants reported: how many years they had been in a caring role with the person they cared for (years: less than one, 1 to 2, 3 to 10,11 to 20 , more than 20); if they lived in the same residence as that person (yes, no, sometimes); what their relationship was to that person (parent, partner, child, sibling, neighbour, friend, other); and that person's primary psychiatric diagnosis (schizophrenia, depression, anxiety disorder, panic disorder, bipolar disorder, post-traumatic stress disorder, eating disorder, personality disorder, unsure, other).

\section{Expectations of care provision}

Participants were asked separate questions for each of four types of health care services: mental health hospitals, community mental health services, GP, and/or NGOs. For each, carers were asked if such a service should provide care for a) fruit and vegetable consumption, and b) physical activity for people with a mental health condition (yes, no, unsure). For instance, 'For someone with a mental health condition, do you think the services below should provide care for fruit and vegetable consumption?'

\section{Health risk behaviour status}

Participants were asked: how many serves of fruit (0, 1, 2 or more, unsure) and vegetables they usually ate each day $(0,1,2,3,4,5$ or more, unsure); and how many days a week they usually did $30 \mathrm{~min}$ or more of physical activity $(0,1,2,3,4,5,6,7$, unsure, can't do physical activity for health or treatment reasons).

\section{Perceived health effects of fruit and vegetable} consumption and physical activity

All participants were asked to respond to four items: 'to what extent do you think eating enough fruit and vegetables can have a positive impact on mental health?'; 'to what extent do you think doing enough physical activity can have a positive impact on mental health?'; 'to what extent do you think not eating enough fruit and vegetables can have a negative impact on mental health?'; and 'to what extent do you think not doing enough physical activity can have a negative impact on mental health?' (not at all, a little, moderately, very, unsure).

\section{Data analysis}

SPSS version 23 [85] was used to analyse the data. Participant postcode was used to determine the geographic remoteness (major cities, regional, rural) and socio-economic index of disadvantage (disadvantaged, average/advantaged) of the area in which they resided [83, 84]. Response categories for socio-demographic and clinical characteristics were collapsed to two or three categories as shown in Table 1; with the exception of psychiatric diagnosis (four categories). Fruit and vegetable consumption and physical activity levels were dichotomised (adequate vs inadequate) based on the Australian national guidelines, [23, 86] where consuming two or more serves of fruit and five or more serves of vegetables each day was adequate, and participating in at least $30 \mathrm{~min}$ of physical activity, at least five days per week was deemed adequate. Items regarding expectations of care provision by the four health and community service settings were condensed to two categories (yes, no or unsure).

Descriptive statistics were used to summarise sociodemographic and clinical characteristics, participants' expectations of care provision by health and community services, risk behaviour status, and perceived effect of fruit and vegetable consumption and physical activity on mental health.

Chi-square analyses using Fisher's Exact test statistic were used to examine possible associations between all independent variables listed in Table 1 and carers' perceptions of the impact of the health risk behaviours on mental health with carers' expectations of care provision for fruit and vegetable consumption and physical activity by each of the four service settings (dependent variables). Independent variables associated at $p<.25$ were subsequently entered into backward stepwise logistic regression models to examine the independent association $(p<.05)$ with expectation of care provision (for fruit and vegetable consumption, and physical activity separately) in each of the four service settings (eight models total).

\section{Results}

Sample characteristics

Of the 371 eligible carers invited to take part; 144 completed the survey (38.8\%); 97 by mail, 46 in a carer 
Table 1 Socio-demographic characteristics

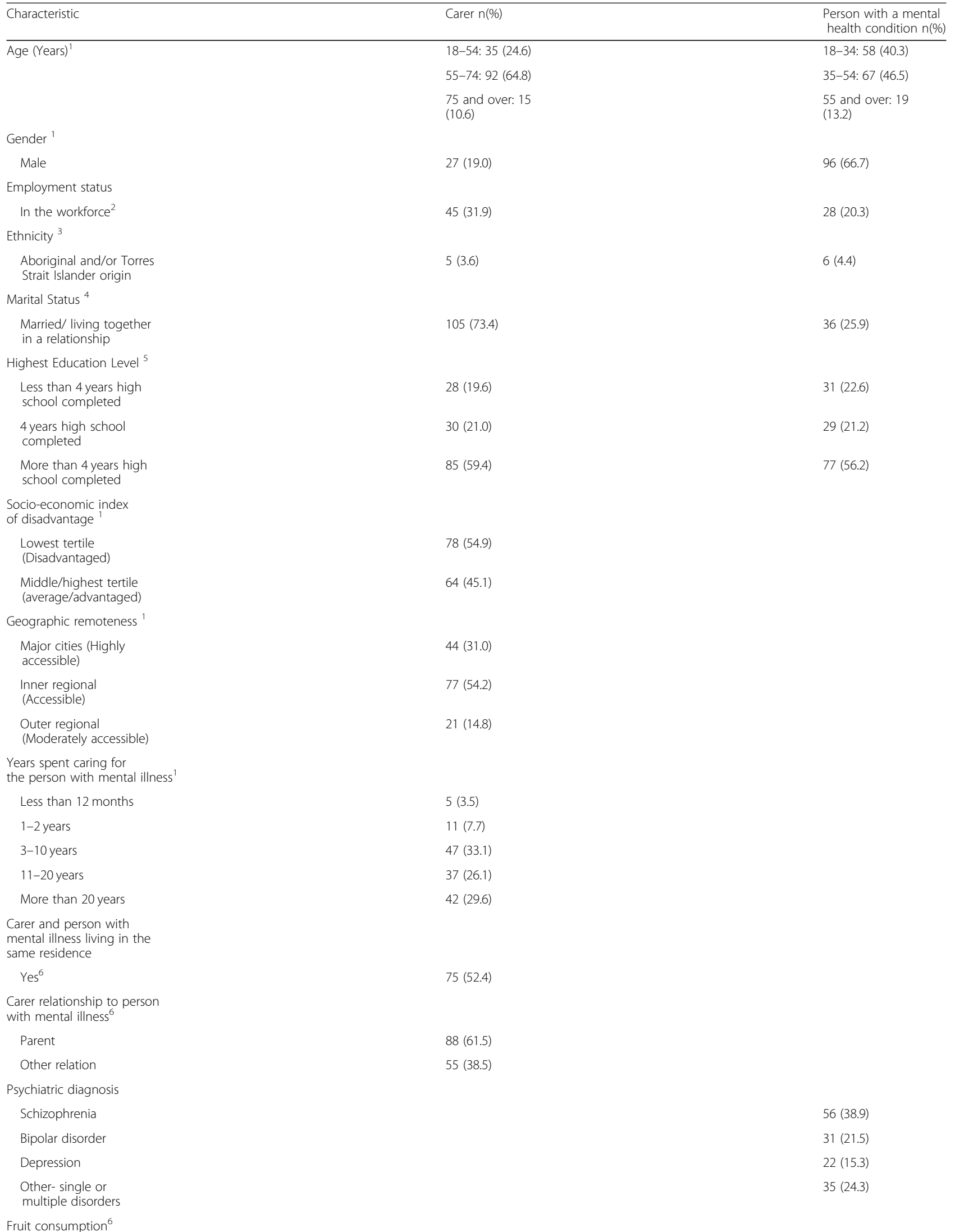


Table 1 Socio-demographic characteristics (Continued)

\begin{tabular}{|c|c|c|}
\hline Characteristic & Carer n(\%) & $\begin{array}{l}\text { Person with a mental } \\
\text { health condition } \mathrm{n}(\%)\end{array}$ \\
\hline Inadequate & $49(34.0)$ & \\
\hline \multicolumn{3}{|c|}{ Vegetable consumption ${ }^{6}$} \\
\hline Inadequate & $98(68.5)$ & \\
\hline \multicolumn{3}{|c|}{$\begin{array}{l}\text { Combined fruit and } \\
\text { vegetable consumption }\end{array}$} \\
\hline Inadequate & $107(74.8)$ & \\
\hline \multicolumn{3}{|c|}{ Physical activity ${ }^{7}$} \\
\hline Inadequate & $76(57.6)$ & \\
\hline $\begin{array}{l}1{ }^{1} \text { Two missing } \\
2 \text { Three missin } \\
{ }^{3} \text { Four missing } \\
{ }^{4} \text { One missing } \\
{ }^{5} \text { One missing } \\
{ }^{6} \text { One missing } \\
{ }^{7} \text { Twelve missi }\end{array}$ & $\begin{array}{l}\text { sponses } \\
\text { responses } \\
\text { enses } \\
\text { esponses }\end{array}$ & \\
\hline
\end{tabular}

support group, and 1 online. Participants who completed the survey in a support group were more likely to be 75 years or older $(21.7 \%$ vs $7.1 \%, p=.005)$ and to live in a major city $(57.8 \%$ vs $18.6 \%, p<.001)$ than participants who completed the survey by post. The majority of participants were female (81.0\%), over the age of 54 (75.4\%), the parent of the person they cared for (61.5\%), and resided with that person (52.4\%; Table 1).

\section{Expectations of care provision}

The majority of participants expected all four types of health care services to provide care for fruit and vegetable consumption to people with a mental health condition, with the highest expectation for GPs $(81.1 \%)$, and the lowest for NGOs (56.2\%) (Table 2). The majority of participants also expected all service settings to provide

Table 2 Expectations of care in health and community service settings

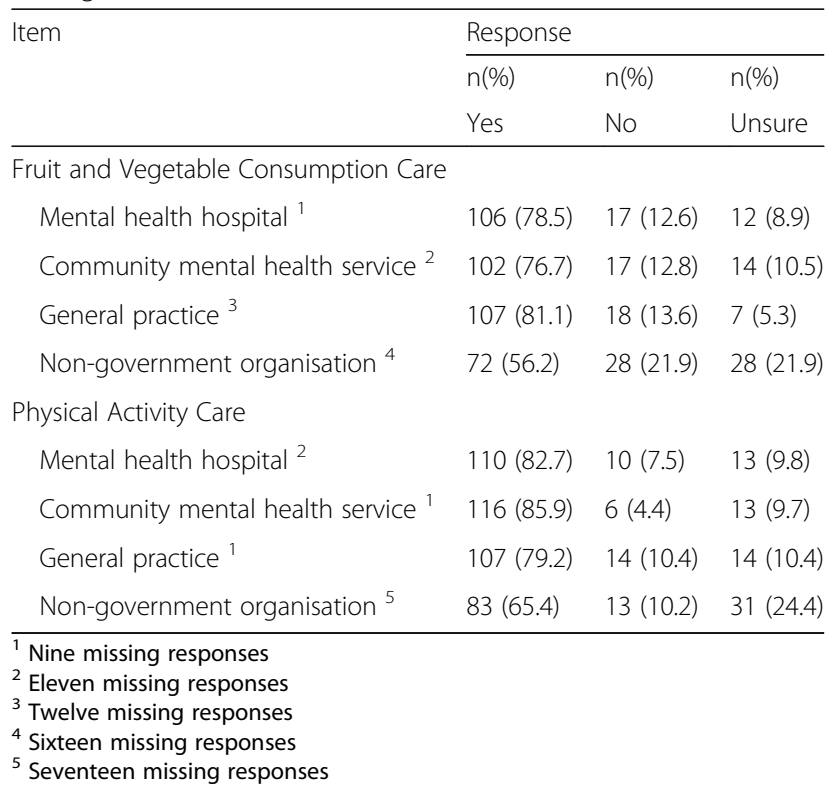

care for physical activity, with the highest expectation for community mental health services (85.9\%), and the lowest for NGOs (65.4\%).

\section{Health risk behaviour status}

The majority of carers were consuming inadequate amounts of vegetables (68.5\%), and approximately one third were consuming inadequate amounts of fruit (34.0\%). The proportion of carers consuming inadequate fruit or vegetables overall was $74.8 \%$. More than half of the carers reported engaging in inadequate amounts of physical activity (57.6\%; Table 1$)$.

\section{Perceived mental health effects of fruit and vegetable consumption and physical activity}

Approximately half the carers perceived that consuming adequate amounts of fruit and vegetables could have a 'very' positive impact on mental health (55.9\%); $48.6 \%$ perceived that inadequate fruit and vegetable consumption would have a 'very' negative impact on mental health. Approximately two thirds of participants perceived that adequate physical activity would have a 'very' positive impact on mental health (71.3\%), and that inadequate physical activity would have a 'very' negative impact on mental health (63.8\%). Very few participants reported that fruit and vegetable consumption or physical activity would have no impact on mental health (2.1 to $7.0 \%$ respectively; Table 3 ).

\section{Associations between socio-demographic and attitudinal} variables, with expectations of care provision

Final regression models are presented in Table 4. Participants perceiving that 'eating enough fruit and vegetables would have a very positive impact on mental health' had greater odds of expecting care for fruit and vegetable consumption to be provided in: mental health hospitals (Odds ratio [OR]: 2.61, 95\% Confidence Interval [CI]: 1.09-6.26, $p=.03$ ); GP (OR: 3.30, 95\% CI: 1.24-8.51, 
Table 3 Perceived health effects of fruit and vegetable consumption and physical activity on mental health

\begin{tabular}{|c|c|c|c|c|c|}
\hline \multirow[t]{3}{*}{ Item } & \multicolumn{5}{|l|}{ Response } \\
\hline & $n(\%)$ & $n(\%)$ & $\mathrm{n}(\%)$ & $\mathrm{n}(\%)$ & $n(\%)$ \\
\hline & Very & Moderately & A little & Not at all & Unsure \\
\hline $\begin{array}{l}\text { Adequate fruit and vegetable consumption- } \\
\text { positive influence on mental health }{ }^{1}\end{array}$ & $80(55.9)$ & $41(28.7)$ & $11(7.7)$ & $6(4.2)$ & $5(3.5)$ \\
\hline $\begin{array}{l}\text { Inadequate fruit and vegetable consumption- } \\
\text { negative influence on mental health }\end{array}$ & 69 (48.6) & $39(27.5)$ & $13(9.2)$ & $10(7.0)$ & $11(7.7)$ \\
\hline $\begin{array}{l}\text { Adequate physical activity- positive influence } \\
\text { on mental health' }\end{array}$ & $102(71.3)$ & $29(20.3)$ & $7(4.9)$ & $3(2.1)$ & $2(1.4)$ \\
\hline $\begin{array}{l}\text { Inadequate physical activity - negative influence } \\
\text { on mental health }\end{array}$ & $90(63.8)$ & $30(21.3)$ & $6(4.3)$ & $7(5.0)$ & $8(5.6)$ \\
\hline
\end{tabular}

${ }^{1}$ One missing response

2 two missing responses

${ }^{3}$ three missing responses

$p=.02$ ); and NGOs (OR: 2.30, 95\% CI: 1.02-5.17, $p=.04$ ), compared to carers not holding that view.

Carers who perceived 'doing enough physical activity would have a very positive impact on mental health' were almost four times more likely to expect care for physical activity in mental health hospitals (OR: 3.70, 95\% CI: 1.44-9.84, $p=<.01$ ), compared to carers not holding that view. Carers who completed four years of high school (School Certificate) had lower odds of expecting physical activity care in community mental health services (OR: .15, 95\% CI: .04-.50, $p=<.01$ ) and GPs (OR: .28, 95\% CI: .10-.80, $p=.02$ ), compared to carers who had completed more than four years high school. There were no other significant associations.

\section{Discussion}

This is the first study to explore the prevalence of family carer expectations regarding care provision for fruit and vegetable consumption and physical activity to people with a mental health condition by a variety of health and community service settings, and factors associated. Many carers expected all four service settings to provide care for fruit and vegetable consumption, (56.2-81.1\%) and physical activity (65.4-85.9\%). The majority of carers consumed inadequate fruits and vegetables and engaged in inadequate physical activity. The majority of carers perceived that consuming adequate amounts of fruits and vegetables and engaging in adequate amounts of physical activity would have a very positive impact on mental health. Perceptions that the health risk behaviours would have a positive impact on mental health was associated with expectations of care. Carers who held the view that adequate fruit and vegetable consumption would have a very positive impact on mental health were more likely to expect such care in mental health hospitals, GP, and NGOs; whilst carers who believed adequate physical activity would have a very positive impact on mental health were more likely to expect care for that risk behaviour in mental health hospitals. Finally, carers who completed four years of high school were less likely, than carers who completed more than four years of high school, to expect physical activity care provision in community mental health services and GP.

The findings of a high prevalence of carers expecting care to be delivered for both health risk behaviours across all care delivery settings studied align with the recommendations of guidelines and policies regarding the provision of physical health care in all services accessed by people with a mental health condition [5155]. The results are also consistent with research reporting that people with a mental health condition would find it acceptable to be provided with support to change health risk behaviours from the services they access [28, 49, 61, 87-89]. Such findings highlight the need for health and community services to adhere to existing policies and increase the provision of care for these health risk behaviours to people with a mental health condition given the reported sub-optimal provision of preventive care to date [63].

Findings from implementation research suggest that in order for such care provision to increase in services accessed by people with a mental health condition, further research is required to develop strategies to overcome barriers to the provision of such care. Identified barriers include: a prioritisation of mental health care over health risk behaviours $[65,90]$; a lack of confidence in providing preventive care $[66,91]$; perceptions of client lack of interest in improving risk behaviours, [9094] and; a lack of client receptivity to receive behaviour change support [91, 95]; a lack of time to provide such care $[96,97]$; lack of training in the provision of care [90, 98]; lack of organisational policies regarding the recording of care provision, [91, 99] and; a lack of reminders to facilitate care provision [97, 100]. Further implementation research is required to identify and understand mental health service characteristics that impede on the provision of preventive care; and subsequently tailor practice change intervention strategies to 
Table 4 Variables associated with expectations of fruit and vegetable consumption and physical activity care provision

\begin{tabular}{|c|c|c|c|}
\hline Predictor & OR & 95\% Cl Lower Upper & $p$ \\
\hline \multicolumn{4}{|l|}{ FRUIT AND VEGETABLE CONSUMPTION } \\
\hline \multicolumn{4}{|l|}{ Mental health hospitals ${ }^{1}$} \\
\hline Fruit and vegetable consumption- very positive impact on mental health & 2.61 & $1.09-6.26$ & $0.03^{*}$ \\
\hline \multicolumn{4}{|l|}{ Community mental health services ${ }^{2}$} \\
\hline Living in same residence & 0.47 & $0.20-1.12$ & 0.09 \\
\hline Married/de facto carers & 0.39 & $0.13-1.24$ & 0.11 \\
\hline \multicolumn{4}{|l|}{$\mathrm{GPs}^{3}$} \\
\hline Carer inadequate nutrition & 0.30 & $0.08-1.12$ & 0.07 \\
\hline Carer in workforce & 3.20 & $0.98-10.45$ & 0.05 \\
\hline Fruit and vegetable- very positive impact on mental health & 3.30 & $1.24-8.51$ & $0.02^{*}$ \\
\hline \multicolumn{4}{|l|}{$\mathrm{NGOs}^{4}$} \\
\hline Carer gender - female & 2.32 & $0.95-5.65$ & 0.07 \\
\hline Fruit and vegetable- very positive impact on mental health & 2.30 & $1.02-5.17$ & $0.04^{*}$ \\
\hline Family member psychiatric diagnosis & & & 0.05 \\
\hline Schizophrenia & 2.63 & $0.95-7.27$ & 0.06 \\
\hline Depression & 0.83 & $0.23-2.97$ & 0.77 \\
\hline Bipolar & 3.42 & $1.04-11.18$ & 0.05 \\
\hline Other & & & Reference \\
\hline \multicolumn{4}{|l|}{ PHYSICAL ACTIVITY } \\
\hline \multicolumn{4}{|l|}{ Mental health hospitals ${ }^{5}$} \\
\hline Physical activity- very positive impact on mental health & 3.70 & $1.44-9.48$ & $<0.01^{*}$ \\
\hline \multicolumn{4}{|l|}{ Community mental health services ${ }^{6}$} \\
\hline Carer highest education level & & & $<0.01^{*}$ \\
\hline Less than four years high school & 0.57 & $0.15-2.21$ & 0.41 \\
\hline Four years high school & 0.15 & $0.04-0.50$ & $<0.01^{*}$ \\
\hline More than four years high school & & & Reference \\
\hline \multicolumn{4}{|l|}{$\mathrm{GPs}^{7}$} \\
\hline Carer highest education level & & & $0.03^{*}$ \\
\hline Less than four years high school & 0.38 & $0.13-1.10$ & 0.07 \\
\hline Four years high school & 0.28 & $0.10-0.80$ & $0.02^{*}$ \\
\hline More than four years high school & & & Reference \\
\hline \multicolumn{4}{|l|}{$\mathrm{NGOs}^{8}$} \\
\hline Carer inadequate physical activity & 0.48 & $0.21-1.10$ & 0.10 \\
\hline Married/de facto carer & 0.39 & $0.14-1.09$ & 0.07 \\
\hline
\end{tabular}

*Significant at $p<.05$

Variables entered intro regression model at $p<.25$ :

1 Carer gender, carer and family member residential status, impact of fruit and vegetable consumption on mental health

2 Carer and family member residential status, carer employment status, carer marital status

${ }^{3}$ Family member age, carer nutrition risk status, impact of fruit and vegetable consumption on mental health, carer employment status

${ }^{4}$ Carer age, carer gender, carer nutrition risk status, impact of fruit and vegetable consumption on mental health, carer highest education level, family member psychiatric diagnosis

${ }^{5}$ Impact of physical activity on mental health, family member highest education level, carer marital status

${ }^{6}$ Carer highest education level, impact of physical activity on mental health, carer marital status, family member marital status, socio-economic index

of disadvantage

${ }^{7}$ Carer highest education level. Family member highest education level

${ }^{8}$ Carer age, years in caring relationship, carer physical activity risk status, carer marital status

address such characteristics within mental health services. From the carer perspective, a limited body of literature exists, however it suggests carers do expect holistic care from services accessed by their family members with a mental health condition $[79,101]$. Future research could seek to explore expectations of care provision further. It may be that carers might prioritise mental health support over physical health support for their loved one. Some might believe that offering nutrition support would likely limit the time available to deliver more traditional mental health support. Some consumers, staff, and carers may not be aware of the 
evidence that there are mental health benefits, as well as physical health benefits, from improving physical activity and nutrition condition [38-41].

Additionally, higher expectations of care for both health risk behaviours were reported by carers compared to the proportion of carers who perceived engaging in positive risk behaviours would have a very positive impact on mental health. Further research is required to explore this trend and confirm is such findings are consistent among a larger sample. It may be that expectations of care provision were also influenced by carer knowledge of the positive impact on physical health to be gained from engaging in positive health risk behaviours $[79,102]$. Subsequent research is required to explore such a speculation.

A perception that the health risk behaviours have an impact on mental health is consistent with previous research among family carers, where carers reported a perception of a bidirectional relationship between physical and mental health, [79] and have expressed expectations for smoking cessation care to be provided to clients with a mental health condition [80]. Similarities were found between the results of the current study and a previous study exploring carer expectations of smoking cessation care by health and community services [80]. Carers, in a previous study, who perceived that smoking cessation would have a positive impact on mental health were more likely to expect smoking cessation care in mental health hospitals, community mental health services, and non-government organisations [80]. Such findings suggest carers are aware of the impact of health risk behaviours on mental health. Given the prioritisation of mental over physical health care by services, reported by carers $[101,103,104]$ and mental health professionals, $[105,106]$ further dissemination of the bidirectional relationship between physical and mental health [37-41] and the knowledge of such a link by carers - may aid in increasing physical health care by services catering to clients with a mental health condition. It may be that carers' knowledge about the link between mental and physical health could be used to advocate for improved preventive care provision in mental health care delivery for their family member.

Carer risk status was not associated with expectations of care for the relevant health risk behaviour in any service studied; similar to a previous study of carer expectations on smoking cessation care by the same service types [80]. Such findings may suggest carers' own risk status may not impact on their perceptions of physical health care for their family members with a mental health condition. Further research is required to explore this finding to determine if carers may have the potential to support health risk behaviour change among people with a mental health condition (which a limited body of research suggests $[78,79,101,102,107,108])$ and if their own risk status may impact on such a potential. Research among mental health professionals suggests the provision of support to change health risk behaviours may be decreased in those professionals engage in health risk behaviours [66].

The association between carer education level and expectations of physical activity care in community mental health services and GP requires further investigation. It has been found in previous research that individuals with lower levels of education have less knowledge of physical activity guidelines [109]. A recent Australia study ( $n=$ 615) found that individuals were more likely to be physically active if they were aware of the benefits of physical activity (knowledge increased risk of disease resulting from physical inactivity) [110]. It may be that participating carers with more than four years of high school completed, may have had an increased knowledge of the benefits of physical activity and thus were more likely to expect care within community mental health services.

The results of this research should be considered in the context of the following limitations. This study had a low response rate $(<38 \%)$, yielding a small sample $(n=144)$, drawn from members of a carer support organisation within one regional local health district in Australia. Caution should be used when considering the results of the regression analyses given the small sample size. The experiences of participating carers may not be representative of all carers of people with a mental health condition, or of carers from different geographical locations. However, the geographic and socio-economic profile of the participants were largely consistent with characteristics of carers in Australia [71]. Additionally, given participants were recruited based on their previous consent to receive invitations to participate in research; such a recruitment strategy may have resulted in selection bias where these carers who have previously elected to participate in research may not be representative of all carers of people with a mental health condition. The self-reported nature of the data may also be prone to recall and social desirability biases [111]; which would perhaps most likely result in an under-estimation of engagement in chronic disease risk behaviours. Some evidence does suggest however that older adults' recall of their health behaviours is reliable [112]. Chronic physical conditions were not assessed in the current study. It is unclear if carers' responses may have differed if their family member with a mental health condition also had a comorbid physical health condition. Future research could aim to assess such comorbidities and the impact on carers' expectations of support from health services. The current study utilised a broad definition regarding care provision. It is unknown if providing additional details regarding care elements, such as asking about risk behaviours and providing advice, may have 
impacted the results. Finally, given the cross-sectional nature of the study, no causal inferences can be made. Future research could seek to explore additional factors that could impact on carer's expectations of care provision in health and community services to people with a mental health condition.

\section{Conclusions}

Given the increasing need to recognise and include family carers as key stakeholders in the provision of care to people with a mental health condition, this research provides novel insight. Findings suggest that many carers are aware of the impact that health risk behaviours can have on mental health and that carers may also expect services accessed by people with a mental health condition to provide care for such risk behaviours. These results reinforce the need for health services to consider providing care for people with a mental health condition that addresses fruit and vegetable consumption and physical activity. Additionally, in line with guidelines recommending the inclusion of client and carer perspectives in service planning, the current findings could be included in discussions regarding the development, provision, and evaluation of new services provided to people with a mental health condition. Future research could explore whether stronger engagement between health services and carers and people with a mental health condition in the development of new services would lead to the implementation of more routine provision of care for chronic disease health risk behaviours.

\section{Supplementary information}

Supplementary information accompanies this paper at https://doi.org/10. 1186/s12913-020-5059-0.

Additional file 1. Carers Views. Addressing Physical Health Risk

Behaviours

\section{Abbreviations}

BMI: Body Mass Index; Cl: Confidence Interval; DALY: Disability Adjusted Life Years; GP: General Practice; NGO: Non-Government Organisation; NSW: New South Wales; OR: Odds Ratio

\section{Acknowledgments}

The authors would like to thank all carer participants for their contribution to the project. The authors would also like to thank all Carer Assist team leaders for their assistance with participant recruitment.

\section{Author's contributions}

Authors JMB, JAB, and PW designed, distributed, and assisted in the conduct of the survey. All authors (JMB, TCM, KB, JW, PW, and JAB) contributed to the article conception, writing, and interpretation of data analyses and editing of the manuscript. Author JMB conducted all data analyses. All authors (JMB, $\mathrm{TCM}, \mathrm{KB}, \mathrm{JW}, \mathrm{PW}$, and JAB) read and approved the final version of the submitted manuscript.

\section{Funding}

This research received no specific grant from any funding agency in the public, commercial, or not-for-profit sectors. Author KB is supported by a National Health and Medical Research Council Early Career Fellowship (\#1142272).

\section{Availability of data and materials}

The dataset used and analysed during the current study is available from the corresponding author on reasonable request.

\section{Ethics approval and consent to participate}

The study was approved by the Hunter New England Human Research Ethics Committee (No. 13/06/19/5.11) and was registered with the University of Newcastle's Human Research Ethics Committee (No. H-2019-0141). All participants provided written informed consent.

\section{Consent for publication}

Not applicable.

\section{Competing interests}

The authors declare that they have no competing interests.

\section{Author details}

${ }^{1}$ School of Psychology, Faculty of Science and Information Technology, The University of Newcastle, University Drive, Callaghan, NSW 2308, Australia. ${ }^{2}$ Hunter Medical Research Institute, Clinical Research Centre, Lot 1 Kookaburra Circuit, New Lambton Heights, NSW 2305, Australia. ${ }^{3}$ Population Health, Hunter New England Local Health District, Booth Building, Wallsend Health Services, Longworth Avenue, Wallsend, Wallsend, NSW 2287, Australia. ${ }^{4}$ School of Medicine and Public Health, Faculty of Health and Medicine, The University of Newcastle, University Drive, Callaghan, NSW 2308, Australia.

Received: 26 November 2019 Accepted: 28 February 2020

Published online: 12 March 2020

\section{References}

1. World Health Organisation. Global status report on noncommunicable diseases 2014. Switzerland: WHO; 2014.

2. World Health Organization. Global health estimates 2016: deaths by cause, age, sex, by country and by region, 2000-2016. Geneva: World Health Organization; 2018.

3. GBD 2017 Risk Factor Collaborators. Global, regional, and national comparative risk assessment of 84 behavioural, environmental and occupational, and metabolic risks of clusters of risks for 195 countries and territories, 1990-2017: A systematic analysis for the Global Burden of Disease Study 2017. Lancet. 2018;392(10):1923-94.

4. World Health Organisation. Global Health Observatory (GHO) data: Overweight and obesity. In: Organisation WH, editor. Geneva2017.

5. Australian Institute of Health and Welfare. Australia's health 2018. Australia's health series no. 16. AUS 221. Canberra: AlHW; 2018.

6. Global B. M. I. Mortality collaboration, Di Angelantonio E, Bhupathiraju Sh N, Wormser D, Gao P, Kaptoge S, et al. Body-mass index and all-cause mortality: individual-participant-data meta-analysis of 239 prospective studies in four continents. Lancet. 2016;388(10046):776-86.

7. Whitlock G, Lewington S, Sherliker P, Clarke R, Emberson J, Halsey J, et al. Bodymass index and cause-specific mortality in 900000 adults: collaborative analyses of 57 prospective studies. Lancet. 2009;373(9669):1083-96.

8. Pomerleau J, Lock K, Knai C, McKee M. Interventions designed to increase adult fruit and vegetable intake can be effective: a systematic review of the literature. J Nutr. 2005;135(10):2486-95.

9. GBD 2017 Diet Collaborators. Health effects of dietary risks in 195 countries, 1990-2017: A systematic analysis for the Global Burden of Disease Study 2017. Lancet. 2019:393:1958-72.

10. World Health Organization. Global action plan on physical activity 20182030: more active people for a healthier world. Geneva: WHO; 2018.

11. Malik VS, Willett WC, Hu FB. Global obesity: trends, risk factors and policy implications. Nat Rev Endocrinol. 2013;9:13-27.

12. Pomerleau J, McKee M, Lobstein T, Knai C. The burden of disease attributable to nutrition in Europe. Public Health Nutr. 2003:6(5):453-61.

13. Lock K, Pomerleau J, Causer L, Altmann DR, McKee M. The global burden of disease attributable to low consumption of fruit and vegetables: implications for the global strategy on diet. Bull World Health Organ. 2005;83(2):100-8.

14. Yusuf HR, Giles WH, Croft JB, Anda RF, Casper ML. Impact of multiple risk factor profiles on determining cardiovascular disease risk. Prev Med. 1998;27(1):1-9.

15. Australian Institute of Health and Welfare. Australian burden of disease study: impact and causes of illness and death in Australia 2011. Canberra: AlHW; 2016. 
16. Piercy KL, Troiano RP, Ballard RM, Carlson SA, Fulton JE, Galuska DA, et al. The physical activity guidelines for AmericansPhysical activity guidelines for AmericansPhysical activity guidelines for Americans. JAMA. 2018;320(19):2020-8.

17. Her Majesty's Government. Factsheet 4: Physical activity guidelines for adults 19-64 years. In: Health Do, editor. London: Her Majesty's Government; 2011

18. Canadian Society for Exercise Physiology. Canadian physical activity guidelines: for adults 18-64 years. Ottawa: Canadian Society for Exercise Physiology; 2011.

19. Ministry of Health. Eating and activity guidelines for New Zealand adults. Wellington: Ministry of Health; 2015

20. U.S. Department of Health and Human Services and U.S. Department of Agriculture. 2015-2020 dietary guidelines for Americans. 8th ed. Washington DC: U.S: Department of Health and Human Services; 2015

21. Public Health England. Government dietary recommendations. London: Public Health England; 2016.

22. Health Canada. Canada's dietary guidelines. Ottawa: Health Canada; 2019.

23. National Health and Medical Research Council. Eat for health: Australian dietary guidelines summary. Canberra: Australian Government; 2013

24. Department of Health. Make your move-sit less be active for life! Canberra: Commonwealth of Australia; 2014.

25. Annamalai A, Kosir $U$, Tek $C$. Prevalence of obesity and diabetes in patients with schizophrenia. World J Diabetes. 2017;8(8):390-6.

26. Luppino FS, de Wit LM, Bouvy PF, Stijnen T, Cuijpers P, Penninx BWJH, et al. Overweight, obesity, and depression: a systematic review and meta-analysis of longitudinal studies. JAMA Psychiatry. 2010;67(3):220-9.

27. Goldstein Bl, Liu S-M, Zivkovic N, Schaffer A, Chien L-C, Blanco C. The burden of obesity among adults with bipolar disorder in the United States. Bipolar Disord. 2011;13(4):387-95.

28. Prochaska JJ, Fromont SC, Delucchi K, Young-Wolff KC, Benowitz NL, Hall S, et al. Multiple risk-behavior profiles of smokers with serious mental illness and motivation for change. Health Psychol. 2014;33(12):1518-29.

29. Smith S, Yeomans D, Bushe C, Eriksson C, Harrison T, Holmes R, et al. A wellbeing programme in severe mental illness. Baseline findings in a UK cohort. Int J Clin Pract. 2007;61(12):1971-8.

30. Laursen TM, Wahlbeck K, Hallgren J, Westman J, Osby U, Alinaghizadeh H, et al. Life expectancy and death by diseases of the circulatory system in patients with bipolar disorder or schizophrenia in the Nordic countries. PLoS One. 2013;8(6):e67133.

31. Brown S, Kim M, Mitchell C, Inskip H. Twenty-five year mortality of a community cohort with schizophrenia. Br J Psychiatry. 2010;196(2):116-21.

32. Bradshaw T, Mairs H. Obesity and serious mental ill health: a critical review of the literature. Healthcare. 2014;2:166-82.

33. APA. Diagnostic and statistical manual of mental disorders. 5th ed. Alrington: American Psychiatric Association Publishing; 2013.

34. Galletly CA, Foley DL, Waterreus A, Watts GF, Castle DJ, McGrath JJ, et al. Cardiometabolic risk factors in people with psychotic disorders: the second Australian national survey of psychosis. Aust N Z J Psychiatry. 2012;46(8):753-61.

35. Australian Institute of Health and Wellbeing. Australia's health 2010 Canberra: AlHW; 2010.

36. Clarke DM, Currie KC. Depression, anxiety and their relationship with chronic diseases: a review of the epidemiology, risk and treatment evidence. Med J Aust. 2009;190:S54-60.

37. Taylor G, McNeill A, Girling A, Farley A, Lindson-Hawley N, Aveyard P. Change in mental health after smoking cessation: systematic review and meta-analysis. Bmj. 2014;348:g1151.

38. Pederson BK, Saltin B. Exercise as medicine - evidence for prescribing exercise as therapy in 26 different chronic diseases. Scand J Med Sci Sports. 2015;25:1-72.

39. Jayakody K, Gunadasa S, Hosker C. Exercise for anxiety disorders: systematic review. Br J Sports Med. 2014;48:187-96.

40. S. R, Tiedemann A, Stanton R, Parker A, Curtis J, Ward PB. Implementing evidence-based physical activity interventions for people with mental illness: an Australian perspective. Australasian Psychiatry. 2016;24(1):49-54.

41. Schuch FB, Vancampfort D, Firth J, Rosenbaum S, Ward PB, Silva ES, et al. Physical activity and incident depression: a meta-analysis of prospective cohort studies. AJP in Advance. 2018.

42. Janney CA, Fagiolini A, Swartz HA, Jakicic JM, Holleman RG, Richardson CR. Are adults with bipolar disorder active? Objectively measured physical activity and sedentary behavior using accelerometry. J Affect Disord. 2014; 152-154:498-504.
43. Kilbourne AM, Morden NE, Austin K, Ilgen M, McCarthy JF, Dalack G, et al. Excess heart-disease-related mortality in a national study of patients with mental disorders: identifying modifiable risk factors. Gen Hosp Psychiatry. 2009:31(6):555-63.

44. Snethen GA, McCormick BP, Lysaker PH. Physical activity and psychiatric symptoms in adults with schizophrenia spectrum disorders. J Nerv Ment Dis. 2014;202(12):845-52.

45. Ussher M, Doshi R, Sampuran A, West R. Cardiovascular risk factors in patients with shcizophrenia receiving continuous medical care. Community Ment Health J. 2011;47:688-93.

46. Simonelli-Munoz A, Fortea M, Salorio P, Gallego-Gomez J, Sanchez-Bautista S, Balanza S. Dietary habits of patients wtih schizophrenia: a self-reported questionnaire survey. Int J Ment Health Nurs. 2012;21(3):220-8.

47. Ringen PA, Faerden A, Antonsen B, Falk RS, Mamen A, Rognli EB, et al. Cardiometabloic risk factors, physical activity and psychiatric status in patients in long-term psychiatric inpatient departments. Nord J Psychiatry. 2018;72(4):296-302.

48. Bartlem K, Bowman J, Bailey J, Freund M, Wye P, Lecathelinais C, et al. Chronic disease health risk behaviours amongst people with a mental illness. Aust N Z J Psychiatry. 2015;49(8):731-41.

49. Bartlem K, Bailey J, Metse AP, Asara A, Wye P, Clancy R, et al. Do mental health consumers want to improve their long-term disease risk behaviours? A survey of over 2000 psychiatric inpatients. Int J Ment Health Nurs. 2017.

50. McElwaine K, Freund M, Campbell E, Knight J, Bowman J, Doherty E, et al. The delivery of preventive care to clients of community health services. BMC Health Serv Res. 2013;13:167.

51. National Institute for Health and Care Excellence. Physical activity: Encouraging activity in all people in contact with the NHS. NICE quality standard 84. National Institute for Health and Care Excellence; 2015.

52. Royal Australian College of General Practitioners. Guidelines for preventive activities in general practice. 9th ed. East Melbourne, Vic: RACGP; 2016.

53. World Health Organisation. 2008-2013 action plan for global strategy for the prevention and control of noncommunicable diseases. Geneva; 2008.

54. Department of Health NSW. Delivery of preventive care in NSW community mental health services. Policy Directive PD2009_027. 2009.

55. Mental Health Commission of NSW. Physical health and mental wellbeing: Evidence guide. Sydney: Mental Health Commission of NSW; 2016.

56. Compton MT, Daumit GL, Druss BG. Cigarette smoking and overweight/ obesity among individuals with serious mental illnesses: a preventive perspective. Harvard review of psychiatry. 2006;14(4):212-22.

57. Verhaeghe N, De Maeseneer J, Maes L, Van Heeringen C, Annemans L. Effectiveness and cost-effectiveness of lifestyle interventions on physical activity and eating habits in persons with severe mental disorders: a systematic review. Int J Behav Nutr Physical activity. 2011;8:28.

58. Cabassa $\amalg$, Ezell JM, Lewis-Fernandez R. Lifestyle interventions for adults with serious mental illness: a systematic literature review. Psychiatr Serv. 2010:61(8):774-82

59. Bonfioli E, Berti L, Goss C, Muraro F, Burti L. Health promotion lifestyle interventions for weight management in psychosis: a systematic review and meta-analysis of randomised controlled trials. BMC Psychiatry. 2012;12:78.

60. Happell B, Davies C, Scott D. Health behaviour interventions to improve physical health in individuals diagnosed with a mental illness: a systematic review. Int J Ment Health Nurs. 2012;21(3):236-47.

61. Bartlem K, Bowman J, Freund M, Wye P, Lecathelinais C, McElwaine K, et al. Acceptability and receipt of preventive care for chronic-disease health risk behaviours reported by clients of community mental health services. Psychiatr Serv. 2015;66(8):857-64.

62. Lord O, Malone D, Mitchell AJ. Receipt of preventive medical care and medical screening for patients with mental illness: a comparative analysis. Gen Hosp Psychiatry. 2010;32(5):519-43.

63. Bailey J, Bartlem K, Wiggers J, Wye P, Stockings E, Hodder R, et al. Systematic review and meta-analysis of the provision of preventive care for modifiable chronic disease risk behaviours by mental health services. Prev Med Rep. 2019;16

64. Happell B, Scott D, Platania-Phung C. Perceptions of barriers to physical health care for people with serious mental illness: a review of the international literature. Issues Ment Health Nurs. 2012;33(11):752-61.

65. Johnson K, Fry C. The attitudes and practices of community managed mental health service staff in addressing physical health: findings from a targeted online survey. Adv Ment Health. 2013;11(3):163-71. 
66. Johnson JL, Malchy LA, Ratner PA, Hossain S, Procyshyn RM, Bottorff JL, et al. Community mental healthcare providers' attitudes and practices related to smoking cessation interventions for people living with severe mental illness. Patient Educ Couns. 2009;77(2):289-95.

67. Knapp M, McDaid D, Mossialos E, Thronicroft G. Mental health policy and practice across Europe. Berkshire: Open University Press; 2007.

68. National Institute for Health and Care Excellence. Schizophrenia: core interventions in the treatment and management of schizophrenia in primary and secondary care (Updated edition) Clinical guideline 82. The British Psychological Society \& The Royal College of Psychiatrists; 2010.

69. National Mental Health Commission. The national review of mental health programmes and services. Sydney: NMHC; 2014.

70. World Health Organization. mhGAP intervention guide for mental, neurological and susbtance use disorders in non-specialized health settings. Geneva: WHO; 2016

71. NSW Department of Health. NSW carers action plan 2007-2012 summary. In: Health NDo, editor. North Sydney: NSW Department of Health; 2007.

72. NSW Mental Health Commission. Living well: a strategic plan for mental health in NSW. Sydney: NSW Mental Health Commission; 2014.

73. Steering Committee for the Review of Government Service Provision. Report on government services 2013. Canberra: Productivity Commission; 2013.

74. Mental Health Council of Australia. Recognition and respect: Mental health carers report 2012. North Sydney: Mental Health Council of Australia; 2012

75. Carer recognition act, (2010).

76. New South Wales Government. NSW carers strategy 2014-2019. Sydney: New South Wales Government; 2014.

77. National Mental Health Commission. Monitoring mental health and suicide prevention reform: National Report 2018. Sydney, NMHC; 2018.

78. Aschbrenner KA, Pepin R, Mueser KT, Naslund JA, Rolin SA, Faber MJ, et al. A mixed methods exploration of family involvement in medical care for older adults with serious mental illness. Int J Psychiatry Med. 2014;48(2):121-33.

79. Bailey JM, Hansen V, Wye PM, Wiggers JH, Bartlem KM, Bowman JA Supporting change in chronic disease risk behaviours for people with a mental illness: A qualitative study of the experiences of family carers. BMC Public Health. 2018;18(416):1-13.

80. Bailey JM, Wye PM, Stockings EA, Bartlem KM, Metse AP, Wiggers JH, et al. Smoking cessation Care for People with a mental illness: family Carer expectations of health and community services. J Smok Cessat. 2016:1-13.

81. Schizophrenia Fellowship of NSW Inc. Carer assist: Support for mental health carers: Schizophrenia Fellowship of NSW Inc.; 2008 [Available from: http://www.sfnsw.org.au/carer-assist/home/Home\#.VEg_kxCukTU.

82. Bartlem K, Bowman J, Freund M, Wye P, McElwaine K, Knight J, et al. Evaluating the effectiveness of a clinical practice change intervention in increasing clinician provision of preventive care in a network of communitybased mental health services: a study protocol of a non-randomised, multiple baseline trial. Implement Sci. 2013;8(85):1-9.

83. Department of Health and Aged Care. Measuring Remoteness: Accessibility/ Remoteness Index of Australia (ARIA). Occasional Papers: New Series Number 14. Canberra: Commonwealth of Australia; 2001.

84. Australian Bureau of Statistics. Technical paper. Socio-economic indexes for areas (SEIFA). Canberra: Australian Bureau of Statistics; 2011

85. Corp IBM. SPSS statistics (version 24). IBM Corp: Armonk, NY; 2016.

86. Department of Health and Aged Care. An active way to better health. Canberra: Australian Government; 1999.

87. Buhagiar K, Parsonage L, Osborn DP. Physical health behaviours and health locus of control in people with schizophrenia-spectrum disorder and bipolar disorder: a cross-sectional comparative study with people with nonpsychotic mental illness. BMC Psychiatry. 2011;11:104.

88. Filia SL, Baker AL, Richmond R, Castle DJ, Kay-Lambkin FJ, Sakrouge R, et al. Health behaviour risk factors for coronary heart disease (CHD) in smokers with a psychotic disorder: baseline results. Ment Health Subst Use. 2011:4(2):158-71.

89. Ussher M, Stanbury L, Cheeseman V, Faulkner G. Physical activity preferences and perceived barriers to activity among persons with severe mental illness in the United Kingdom. Psychiatr Serv. 2007;58(3):405-8.

90. Chwastiak L, Cruza-Guet MC, Carroll-Scott A, Sernyak M, Ickovics J. Preventive counseling for chronic disease: missed opportunities in a community mental health center. Psychosomatics. 2013;54(4):328-35.

91. Price JH, Ambrosetti LM, Sidani JE, Price JA. Psychiatrists' smoking cessation activities with Ohio community mental health center patients. Community Ment Health J. 2007;43(3):251-66.
92. Robson D, Haddad M, Gray R, Gournay K. Mental health nursing and physical health care: a cross-sectional study of nurses' attitudes, practice, and perceived training needs for the physical health care of people with severe mental illness. Int J Ment Health Nurs. 2013;22(5):409-17.

93. Happell B, Scott D, Platania-Phung C, Nankivell J. Should we or shouldn't we? Mental health nurses' views on physical health care of mental health consumers. Int J Ment Health Nurs. 2012;21(3):202-10.

94. Hyland B, Judd F, Davidson S, Jolley D, Hocking B. Case managers' attitudes to the physical health of their patients. Aust N Z J Psychiatry. 2003;37(6):710-4.

95. Ashton M, Lawn S, Hosking JR. Mental health workers' views on addressing tobacco use. Aust N Z J Psychiatry. 2010;44(9):846-51.

96. Organ B, Nicholson E, Castle D. Implementing a physical health strategy in a mental health service. Australas Psychiatry. 2010;18(5):456-9.

97. Happell B, Scott D, Nankivell J, Platania-Phung C. Screening physical health? Yes! But...: nurses' views on physical health screening in mental health care. J Clin Nurs. 2013;22(15-16):2286-97.

98. Nash M. Physical care skills: a training needs analysis of inpatient and community mental health nurses. Ment Health Pract. 2005;9(4):20-3.

99. Dunbar L, Brandt T, Wheeler A, Harrison J. Barriers and solutions to implementing metabolic risk assessment in a secondary mental health service. Australasian Psychiatry. 2010;18(4):322-5.

100. Anderson AE, Bowman JA, Knight J, Wye PM, Terry M, Grimshaw S, et al. Smoking cessation care provision and support procedures in Australian community mental health centers. Psychiatr Serv. 2013;64(7):707-10.

101. Lawn S, McNaughton D, Fuller L. What carers of family members with mental illness say, think and do about their relative's smoking and the implications for health promotion and service delivery: a qualitative study. Int J Ment Health Promot. 2015;17(5):261-77.

102. El-Mallakh P, Yates BE, Adkins S. Family caregiving for adults with schizophrenia and diabetes mellitus. Issues Mental Health Nurs. 2013;34(8):566-77.

103. Happell B, Wilson K, Platania-Phung C, Stanton R. Physical health and mental illness: listening to the voice of carers. J Ment Health. 2016.

104. Missen RL, Brannelly T, Newton-Howes G. Qualitative exploration of family perspectives of smoke-free mental health and addiction services. Int J Ment Health Nurs. 2013;22(4):294-303.

105. Connolly M, Floyd S, Forrest R, Marshall B. Mental health nurses' beliefs about smoking by mental health facility inpatients. Int J Ment Health Nurs. 2013;22(4):288-93

106. Wye P, Bowman J, Wiggers J, Baker A, Knight J, Carr V, et al. Total smoking bans in psychiatric inpatient services: a survey of perceived benefits, barriers and support among staff. BMC Public Health. 2010;10:372.

107. Bailey JM, Wye PM, Wiggers JH, Bartlem KM, Bowman JA. Family carers: a role in addressing chronic disease risk behaviours for people with a mental illness? Prev Med Rep. 2017:7:140-6.

108. Mavundla TR, Toth F, Mphelane ML. Caregiver experience in mental illness: a perspective from a rural community in South Africa. Int J Ment Health Nurs. 2009;18(5):357-67.

109. Knox ECL, Esliger DW, Biddle SJH, Sherar LB. Lack of knowledge of physical activity guidelines: can physical activity promotion campaigns do better? BMJ Open. 2013;3(12):e003633-e.

110. Fredriksson SV, Alley SJ, Rebar AL, Hayman M, Vandelanotte C, Schoeppe S. How are different levels of knowledge about physical activity associated with physical activity behaviour in Australian adults? PLoS One. 2018;13(11): e0207003.

111. Van de Mortel TF. Faking it: social desirability response bias in self-report research. Aust J Adv Nurs, The. 2008;25(4):40.

112. Dal Grande E, Fullerton S, Taylor AW. Reliability of self-reported health risk factors and chronic conditions questions collected using the telephone in South Australia, Australia. BMC Med Res Methodol. 2012;12(1):108.

\section{Publisher's Note}

Springer Nature remains neutral with regard to jurisdictional claims in published maps and institutional affiliations. 